\title{
Tragic death of a family due to house fire
}

\author{
Prasadini SMD Senarath $^{{ }^{*}} \triangle_{\mathrm{h}}$ iD ura SA Nandasiri ${ }^{1}$, Muditha Vidanapathirana ${ }^{1}$ \\ ${ }^{1}$ Department of Forensic Medicine, Faculty of Medical Sciences, University of Sri \\ Jayewardenepura, Sri Lanka.
}

In the early days, hazards of fire were limited to its thermal hazards. With the advancement of civilization, science and industry, the lifestyles of people have changed, including their housing trends, i.e. space, insulation and ventilation, the hazards of other components of the fire has surfaced. Three family members and a niece were found dead inside their airtight, locked house, in a morning by the driver. The pantry area which opened into the living room had evidence of fire. At the autopsy, all four bodies were covered with black soot, but there were no burns in bodies or clothing. The cause of deaths was given as death due to smoke inhalation. The circumstance of the deaths was ascertained as accidental. Even though deaths due to smoke inhalation are rare, with air-conditioning and insulation of houses, the hazards of smoke have increased in Sri Lanka. Therefore, installations of smoke alarms or fire sprinkler systems are recommended to prevent such deaths in the future.

Keywords: Carbon monoxide poisoning, smoke inhalation, house fire

Copyright: @ 2018 with the Medico-legal Journal of Sri Lanka.

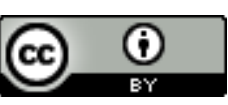

This is an open-access article distributed under the terms of the Creative Commons Attribution 4.0 International License, which permits unrestricted use, distribution and reproduction in any medium provided the original author and source are credited.

Funding: None, Competing interests: None

Received: 23 Oct 2018 Accepted revised version: 15 Dec 2018 Published: 30 December 2018

*Corresponding author:Senarath SMDP, E-mail address: prasadini_senarath@yahoo.com, $\square$ http://orcid.org/0000-0001-6434-0184

Cite this article as:Senarath SMDP, NandasiriSAC, Vidanapathirana M. Tragic death of a family due to house fire.Medico-Legal Journal of Sri Lanka, 2018;6(2):88-91.

DOI: http://dx.doi.org/10.4038/mljsl.v6i2.7381

\section{Introduction}

Fire is one of the most important discoveries of human life. It has changed life in a positive manner in many ways. However, it has its own disadvantages too. In the early days, hazards of the fire were limited to its thermal hazards. With the advancement of civilization, science and industry, the lifestyles of people have changed, including their housing trends, i.e. lack ofspace, insulation and poor ventilation, the hazards of other components of the fire has surfaced.
Though house fires are not common in Sri Lanka, it is an important cause of injury and death in the United States, accounting for about 17000 casualties and 3000 deaths each year. ${ }^{[1]}$ This case under discussion highlights the hazards of fire with the advancement of our lifestyle.

\section{Case report}

A 65-year-old businessman, his 53-year-old wife, 13year-old daughter and 13-year-old niece who came to 
visit them were found dead inside their airconditioned, airtight, locked house, in a morning by the driver who came for duty at the house. When the front door was broke open by the police, the floor, ceiling, furniture and rest of the interior of the house were found blackened with soot. The man's body was found slumped on a chair in the living room, near the front door (Fig. 01). The wife was found lying on the floor of the master bedroom (Fig. 02) and two children were found lying on the floor of the living room at two different places (Fig. 03).

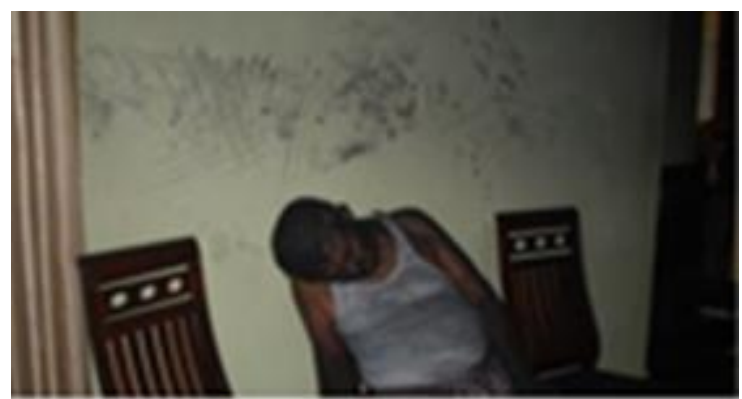

Figure 01: Father's body was found on a chair near the front door.

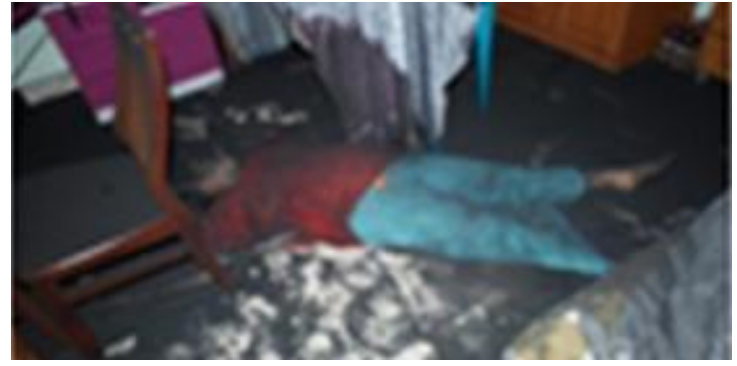

Figure 02: The mother was found lying on the floor of the master bedroom

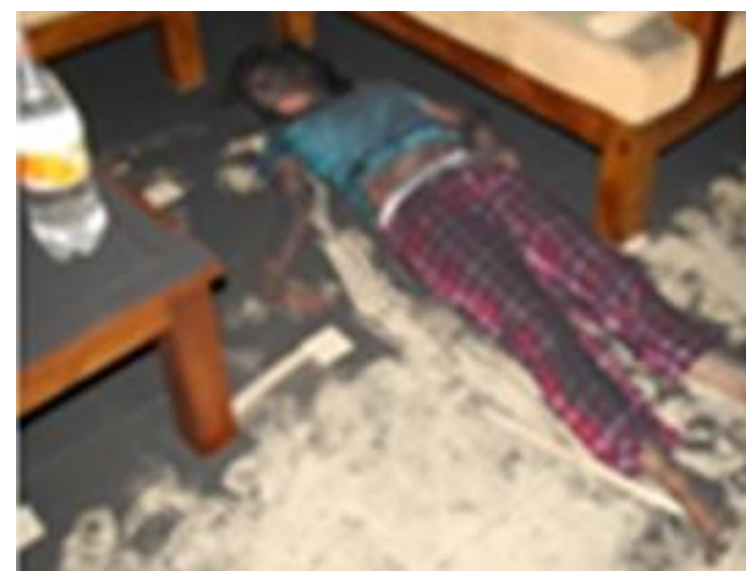

Figure 03: Two children were found lying on the floor of the living room at two different places
There were soot free footprints on the floor and black fingerprints on the wall near the front door.

The pantry area which freely opened into the living room had evidence of fire. There was a burnt mobile phone charger, which was connected to a plug point with an intact phone, with the maximum burnt area surrounding it (Fig. 04). Wooden pantry cupboards were partially burnt and most plastic equipment in that area found to be melted. The escape points such as doors and windows were not nailed from outside.

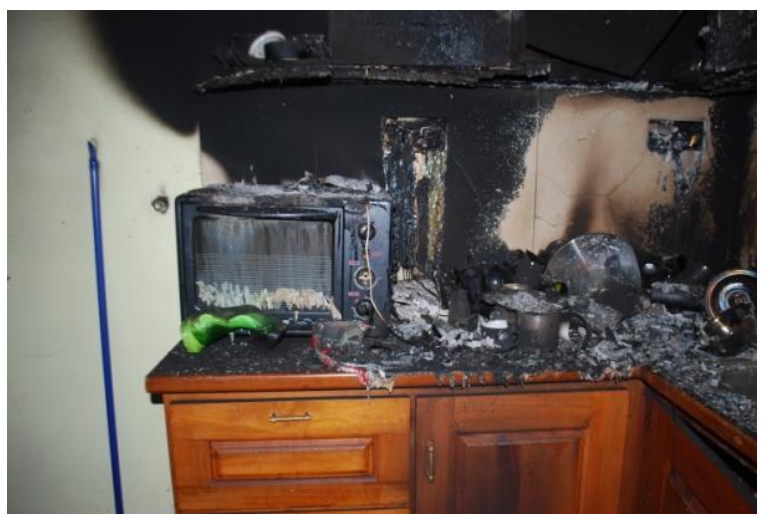

Figure 04: The suspected origin of the fire

At the autopsy, all four bodies were covered with black soot, with no burns in the bodies or clothing. They were clad in night clothes. All bodies had cherry pink hypostasis on dependent areas (Fig. 05).

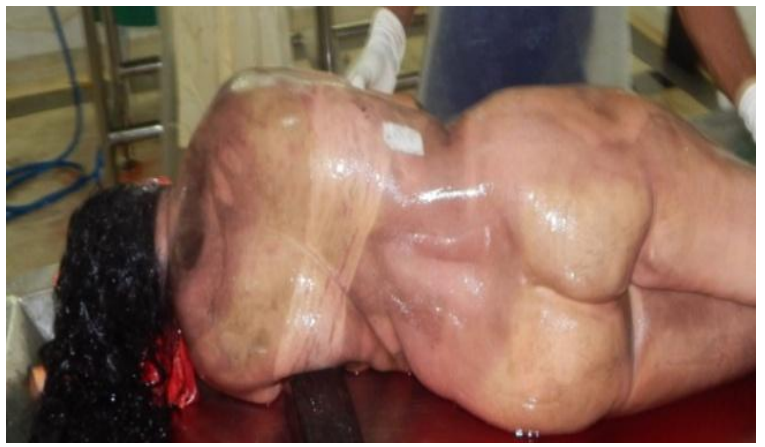

Figure 05: Cherry pink Hypostasis

Soot mixed with mucus was found in the nostrils, mouth, upper airways and lower airways spreading beyond secondary bronchioles (Fig. 06). On musculo-skeletal dissections, no injuries suggestive of intentional violence were identified in any of the bodies. 


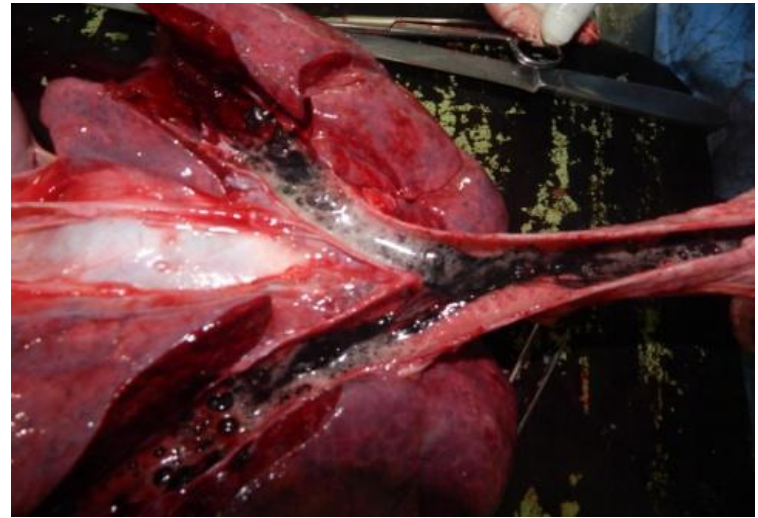

Figure 06: Soot mixed with mucus in the airways

Blood samples sent to the Government Analyst Department were positive for Carbon Monoxide and Cyanide and were free of other toxins.

Histopathology of the lungs showed soot beyond secondary bronchioles, pulmonary congestion and haemorrhages (Fig. 07). The electrical expert confirmed the site of origin of the fire as the mobile charger. The cause of death was given as death due to smoke inhalation.

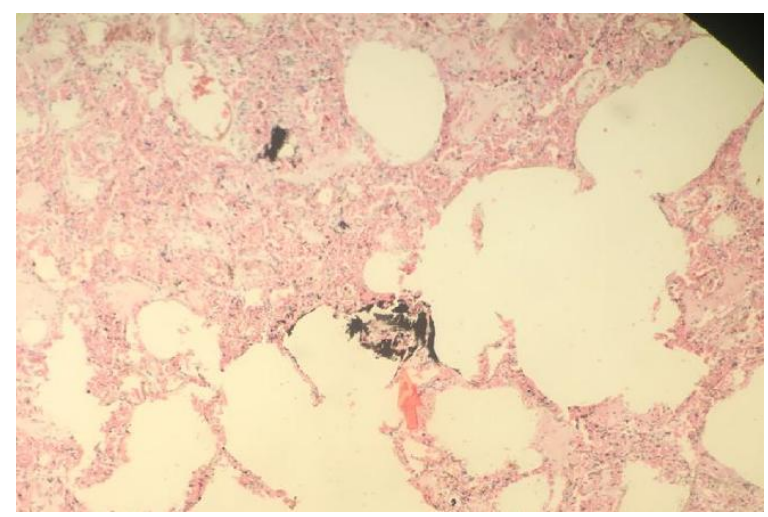

Figure 07: Microphotograph showing soot in lung tissue, pulmonary congestion and pulmonary haemorrhages

\section{Discussion}

Majority of accidental fire deaths occur inside buildings. Usually, fires inside buildings start by ignition and as a small fire, which then spread to produce more heat and smoke. At early stages of the fire, it is fuel-controlled and usually not affected by the enclosure. Then it grows at a slow or fast rate depending on the fuel type and the ventilation available. Smouldering/flameless fires have slow and lengthy growth period and it may extinguish spontaneously without reaching to a fully developed state. $^{[2]}$

Although all the fires are different, they usually share many similar characteristics. According to the literature, the progression, magnitude and toxic threats of fire will differ depending on whether the person is in the room of origin or away from the room of origin, whether the person is awake or in sleep and whether the person is capable or incapable of escaping such as infants, elderly or intoxicated. ${ }^{[3]}$

If the person is in the room of origin of the fire, the immediate effects would be a large number of organic and inorganic chemicals in the smoke causing sensory irritation of the eyes with increased lacrimation resulting in impaired vision, coughing or chocking following bronchial irritation, heat-induced effects and high smoke density causing limitation of vision. Although there is some disorientation, the normal individual's natural reaction would be an attempt to escape from the scene. ${ }^{[3]}$ In this case, the victims were in night clothes and found dead at 4 random places with foot and palm print evidence of volitional activities. There were indications of some volitional activity in all four victims before the death in the form of walking and touching the walls with hands with soot, which indicate that they had tried to escape probably in a semi-conscious state. Further, those suggested that they had attempted to escape but had failed. However, there was no evidence of intentional attempts of preventing their escape such as incapacitation with injuries or poisoning or blocking of escape routes such as door or windows by nailing them from outside etc.

The spreading of smoke will form a hot layer at the ceiling level first, later spreading down towards the floor. This will reduce the level of oxygen $\left(\mathrm{O}_{2}\right)$ and when the level becomes less than $7 \%$ it is a major cause of incapacitation and death. ${ }^{[3]}$ Smoke will contain carbon monoxide $(\mathrm{CO})$ which is a dangerous and potentially lethal gas. ${ }^{[4]}$ Usually, very high $\mathrm{CO}$ concentrations are needed to cause carboxyhaemoglobin (COHb) of $50-60 \%$ in blood. If the burning material contains nitrogen $\left(\mathrm{N}_{2}\right)$, hydrogen cyanide (HCN) will be emitted which is much more dangerous than $\mathrm{CO}$, due to more potency 
to be absorbed when inhaled and its quick action on tissues. ${ }^{[5,6]}$ If the burning material contains chlorine, bromine or fluorine(eg. PVC burning) hydrogen chloride $(\mathrm{HCl})$, phosgene, hydrogen bromide $(\mathrm{HBr})$ or hydrogen fluoride (HF) would be emitted exacerbating the irritation and chocking effects of smoke. Further, these may cause delayed long lasting pulmonary effects in survivors. ${ }^{[7]}$ In this case, $\mathrm{CO}$ and $\mathrm{CN}$ were found in blood, however, their quantitative assessments were not performed.

If the person is placed away from the origin of the fire, heat and $\mathrm{O}_{2}$ depletion would not be much important in causing death. Incapacitation and death would be due to the combined effects of $\mathrm{CO}, \mathrm{HCN}$ and other toxic gases. ${ }^{[3]}$ In the case under discussion, no burn injuries were detected in any of the victims. Cherry red hypostasis and positive $\mathrm{CN}$ and $\mathrm{CO}$ in blood indicated that the deaths were due to toxic gas inhalation. The absence of heat effects on any of the bodies indicated that they were considerably away from the origin of the fire.

The presence of soot mixed mucus in the trachea and beyond secondary bronchioles, reconfirmed with histopathology indicated that they were alive at the time of the onset of fire. This could also have been supported had the Government Analyst performed quantitative analysis of $\mathrm{CO}$ and its concentrationexceeded $10 \%$.

This is a known hazard of sleeping in fully airtight houses, especially with inadvertent plugging of instruments like mobile phones which can get heated and become a source of the fire. Since this is a major health hazard in the Western world, they have recommended the installation of smoke alarms or fire sprinkler systems and to have an escape plan with at least two exit points in households, especially when the rooms are airtight. ${ }^{[8]}$ In Sri Lanka, air-conditioning with insulation of houses are being on the rise.

\section{Conclusions}

The circumstance of the deaths was ascertained as accidental. Even though such deaths due to smoke inhalation are rare, with air-conditioning and insulation of houses, the hazards of smoke have increased in Sri Lanka. Therefore, installations of smoke alarms or fire sprinkler systems are recommended to prevent such deaths in the future.

\section{References}

1. Istre GR. McCoy MA, Osborn L, Bernard JJ, Bolton A. Deaths and injuries from house fire. N Eng J Med. June 2001;344(25): 1911-6

2. Alarifi AA, Phylaktou HN, Andrew GE. What Kills People in a Fire? Heat or Smoke? ${ }^{\text {th }}$ Saudi students Conference, University of Birmingham. Feb 2016.

3. Alarie Y. Toxicity of Fire smoke. Critical Review in Toxicology. 32(4):259-89

4. Anderson RA, Watson AA, Harland WA. Fire Deaths in the Glasgow Area: 11 Role of Carbon Monoxide. Medicine, Science and Law. 1981;21(4):288-94

5. Antonio ACP, Castro PS, Freire LO. Smoke Inhalation during Enclosed Space fires: an Update. Journal of BrasilianPneumology. 2013; 39(3): 373-81

6. Anderson RA, Harland WA. Fire deaths in the Glasgow area. III. The role of hydrogen cyanide. MedSci Law. 1982; 22(1):35-40.

7. Detwiler-Okabayashi K, Schaper M. Evaluation of respiratory effects of thermal decomposition products following single and repeated exposures of guinea pigs. Arch. Toxicol.1995; 69(4): 215-27

8. American Academy of Paediatrics. Reducing the Number of Deaths and Injuries from Residential Fires. Paediatrics. 2000;105(6): 1355-7. 